\title{
Educação superior para o desenvolvimento econômico: um olhar sobre os governos FHC (1995-2002) e Lula (2003-2010)
}

\author{
Uriel Boianovsky Kveller ${ }^{1}$ \\ Ronaldo Herrlein Júnior ${ }^{2}$
}

\begin{abstract}
RESUMO
O desenvolvimento econômico pode ser compreendido como a passagem de uma economia baseada em ativos primários, de baixo valor agregado e explorados por trabalhadores não especializados, para uma economia de ativos baseados no conhecimento e explorados por mão de obra especializada. O Brasil é um país cuja produção industrial e de serviços complexos, de maior agregação de valor, vem regredindo, enquanto sua pauta exportadora é composta em grande parte por produtos primários ou semiindustrializados. Além disso, enfrenta uma série de desafios que impõem dificuldades à qualificação dos trabalhadores. As instituições de ensino superior (IES) podem contribuir para fomentar o processo de desenvolvimento, pois produzem conhecimento científico e formam quadros profissionais especializados. O presente artigo procura identificar e avaliar de forma comparativa as políticas de educação superior e seus resultados consolidados durante os governos de Fernando Henrique Cardoso (1995-2002) e de Luís Inácio Lula da Silva (2003-2010), assumindo a existência de relações significativas entre o ensino superior e o desenvolvimento econômico e visando evidenciar em que medidas tais políticas contribuíram para esse processo.
\end{abstract}

Palavras-chave: desenvolvimento econômico; ensino superior; conhecimento.

\section{Higher education for economic development: an overview on FHC and Lula governments}

\begin{abstract}
Economic development can be understood as the transition from an economy based on primary assets, low value-added and exploited by unskilled workers, to an economy of knowledge-based assets and exploited by skilled labor. Brazil is a country whose industrial production and complex services, with greater aggregation of value, has been regressing, while its export agenda is largely composed of primary or semi-industrialized products. In addition, it faces a series of challenges that pose difficulties to the qualification of workers. Higher education institutions (HEIs) can contribute to fostering the development process because they produce scientific knowledge and form specialized professional staff. This article aims to identify and evaluate in a comparative way the policies of higher education and its consolidated results during the governments of Fernando Henrique Cardoso (1995-2002) and Luís Inácio Lula da Silva (2003-2010), assuming the existence of significant relationships between higher education and economic development, and seeking to show to what extent such policies contributed to this process.
\end{abstract}

Keywords: economic development; higher education; knowledge.

\section{INTRODUÇÃO}

O avanço dos sistemas de produção em escala global e o notório progresso das tecnologias produtivas impõem uma série de desafios à economia mundial, os quais se

\footnotetext{
${ }^{1}$ Mestrando em Economia pela Universidade Estadual de Campinas (Unicamp). urielkveller@gmail.com

${ }^{2}$ Prof. do Departamento de Economia e Relações Internacionais da Universidade Federal do Rio Grande do Sul
} 
vinculam, em maior ou menor grau, ao conhecimento científico e ao conhecimento técnico. Economias em atraso, como as latino-americanas, não produzem, em grande parte, o conhecimento científico de fronteira que engendra as mais variadas inovações. Na verdade, se limitam a observar e imitar o que é produzido em economias avançadas.

Segundo Arocena e Sutz (2005), essa polarização desfavorável às economias que não produzem o conhecimento científico de fronteira só pode ser superada pelo processo de catching up, isto é, o emparelhamento das estruturas produtivas - e da sua base subjacente de conhecimento tecnológicos - em conformidade às economias avançadas. Para realizá-lo, na visão de Lall (2003), é imprescindível que se desenvolvam localmente as capacidades de aprendizado dos trabalhadores, o conjunto de qualidades que torna o trabalho eficiente e com potencial para gerar inovações tecnológicas. Para se ter uma ideia do estágio desse conjunto em uma determinada economia, Lall (2003) sugere como indicador o nível de escolaridade dos trabalhadores. Segundo o autor, esse indicador guarda uma relação direta com o conjunto de capacidades de aprendizado: quanto maior é o nível de escolaridade, mais eficiente e potencialmente inovador será o trabalhador.

O objetivo geral deste artigo é apresentar os resultados consolidados do sistema de ensino superior brasileiro durante dois governos da história recente do país. Inicialmente, delimitaremos o conceito de desenvolvimento econômico e identificaremos algumas de suas relações com a educação superior. A seguir, apresentaremos uma análise da rede física, do alunado matriculado, do alunado por área de conhecimento e das políticas públicas voltadas para o sistema de ensino superior. Por fim, reuniremos as principais conclusões de cada etapa para um balanço comparativo dos dois governos, buscando evidenciar em que medida suas políticas para educação superior contribuíram para o desenvolvimento econômico nacional.

\section{DESENVOLVIMENTO ECONÔMICO E ENSINO SUPERIOR}

O desenvolvimento econômico é, em primeiro lugar, um recorte específico de um processo mais amplo de desenvolvimento humano em sociedade. Segundo Furtado (1980), a ideia de desenvolvimento remete a uma situação de desequilíbrio entre o homem e o meio em que vive. Para equilibrá-lo, ele necessita transformá-lo, de forma individual e coletiva. Um conjunto de indivíduos, no exercício pleno de suas potencialidades, engendra o desenvolvimento e transforma a sociedade. Como o desenvolvimento se dá pela realização de potencialidades, o conceito possui uma conotação claramente positiva. 
Furtado (1980) identifica ao menos três dimensões do desenvolvimento: a) uma dimensão material, que se refere à revolução permanente das bases técnicas de produção e ao aumento no fluxo de bens e serviços superior ao crescimento demográfico; b) a satisfação das necessidades básicas da população; c) o cumprimento de objetivos das classes dominantes perante um cenário de recursos escassos. Cabe ressaltar que essas dimensões podem ser independentes: ganhos de produtividade, por exemplo, não resultam automaticamente em melhoria de serviços públicos básicos, assim como uma distribuição de renda mais igualitária não depende de variações quantitativas do setor produtivo.

Entretanto, a dimensão material é comumente vista como o principal indicador de desenvolvimento, sendo a que mais se aproxima das primeiras ideias a respeito do conceito de desenvolvimento econômico. Como apontado, trata-se do aumento no fluxo de bens e serviços superior ao crescimento demográfico. Tendo em vista a definição de um sentido estrito, o desenvolvimento econômico pode ser compreendido como "um processo em que se passa de um conjunto de ativos baseados em produtos primários, explorados por mão-de-obra não especializada, para um conjunto de ativos baseados no conhecimento, explorados por mão-deobra especializada" (AMSDEN, 2004, p. 29). ${ }^{3}$ Essa perspectiva considera que o desenvolvimento das tecnologias produtivas de um determinado país - capital e trabalho - é fundamental para o desenvolvimento econômico.

Embora cada país comporte particularidades, existem determinantes estruturais do desenvolvimento tecnológico que são compartilhados pelos países em desenvolvimento. Segundo Lall (2003), um desses determinantes é o conjunto de capacidades dos trabalhadores. Os detentores dessas capacidades - de indivíduos ou empresas, dependendo da escala e da complexidade do processo de produção - conseguem produzir e distribuir os seus produtos com vantagens de custo (menor) ou preço (maior) frente aos demais competidores no mercado (AMSDEN, 2004).

Esse conjunto de capacidades tem origem na educação formal, nos treinamentos das firmas, na prática do trabalho e nas especializações fora das firmas. Sendo assim, tanto as firmas quanto as escolas contribuem nesse sentido, em especial as IES, pois oferecem uma formação de maior complexidade, sendo mais importantes para o acesso às tecnologias mais modernas (LALL, 2003).

\footnotetext{
${ }^{3}$ Conforme a abordagem neoschumpeteriana e institucionalista adotada por Amsden, um "ativo baseado no conhecimento" é um conjunto de habilidades que permitem ao detentor produzir e distribuir um produto abaixo dos custos ou acima dos preços normais de mercado. Essas habilidades são, quanto à sua natureza, tecnológicas ou administrativas, podendo ser de base científica ou artesanal (AMSDEN, 2004, p. 29).
} 
Depreende-se que os cursos de graduação influenciam positivamente na capacidade de compreensão de tecnologias e de conhecimentos externos pela sociedade, o que dá margem ao uso mais eficiente e, pois, à redução dos custos econômicos das transferências tecnológicas. A inserção de profissionais com nível superior completo no mercado de trabalho possibilita que as firmas tenham maior capacidade de criação e se tornem menos dependentes das instituições universitárias (CHIARINI; VIEIRA, 2012).

Além disso, o sistema de ensino superior, especialmente os cursos de graduação, pode ensejar a inovação tecnológica: quando entram nas firmas, os egressos das IES levam consigo não apenas o conhecimento científico recentemente adquirido, mas também as habilidades tácitas do conhecimento, as quais são úteis na resolução de problemas complexos, no desenvolvimento de novas ideias e na realização de pesquisas (VELHO, 2007). Segundo Velho (2007), dentre todos os benefícios que a educação superior propicia para o processo de inovação - seja para a sociedade em geral ou para o setor produtivo - a formação de recursos humanos é o de maior relevância.

Desse modo, o número de estudantes matriculados nas IES é uma informação relevante para a análise da formação de profissionais qualificados. Por meio desse dado, pode-se não só verificar a quantidade total de estudantes matriculados no ensino superior, como também especificar o número de matrículas por áreas do conhecimento, procedimento que permite visualizar a distribuição do alunado por cursos, e, consequentemente, se existe (ou não) uma concentração em uma ou mais áreas. Tendo em vista a avaliação das capacidades de absorção do conhecimento técnico, depreende-se que as matrículas relativas à área da Engenharia são as mais significativas, o que torna desejável uma grande quantidade de estudantes nesse campo do conhecimento (LALL, 2003).

No caso brasileiro, Chiarini e Vieira (2012) reforçam a importância relativamente maior da área da Engenharia, visto que a situam no conjunto de áreas estratégicas para o desenvolvimento do país. Os engenheiros ocupam-se, em parte, dos setores dos semicondutores e dos bens de capital, caracterizados pelo seu dinamismo crescente e sustentável, pela sua abertura a novas oportunidades de negócios e, por fim, por se relacionarem intensamente com os processos de inovação tecnológica (CHIARINI; VIEIRA, 2012).

Portanto, o sistema de ensino superior e a quantidade relativa de estudantes de Engenharia matriculados são questões relevantes para o aprimoramento do conjunto de capacidades locais e, em última instância, para o desenvolvimento econômico. 


\section{O ENSINO SUPERIOR NO GOVERNO FHC (1995-2002)}

Com o advento do Plano Real, Fernando Henrique Cardoso foi eleito Presidente da República em 1995, totalizando oito anos no cargo, um feito inédito até então. Tanto o primeiro plano de governo quanto o segundo se debruçaram sobre a educação do país, inclusive sobre a educação superior. Em linhas gerais, eles afirmaram que a Taxa Bruta de Participação (TBP) do país - ilustrada na Figura 1 -, isto é, a proporção de jovens em idade escolar (de 18 a 24 anos) matriculados no ensino superior, era baixa se comparada à taxa de outros países latinoamericanos. Para corrigir esse problema, o Governo FHC propunha o estabelecimento de parcerias entre o Governo Federal e o setor privado, bem como entre instituições universitárias e indústrias, tanto para a gestão quanto para o financiamento do desenvolvimento científico e tecnológico do país.

Conforme mostra a Figura 1, nos primeiros quatro anos do Governo FHC, a TBP praticamente ficou inalterada. Nos anos seguintes esse indicador atingiu o nível de 15\% aproximadamente, o que significava, à época, que a cada 100 (cem) jovens brasileiros em idade escolar, 15 (quinze) estavam matriculados em cursos de ensino superior.

Figura 1 - TBP do Ensino Superior (\%) - 1995, 1998 e 2002

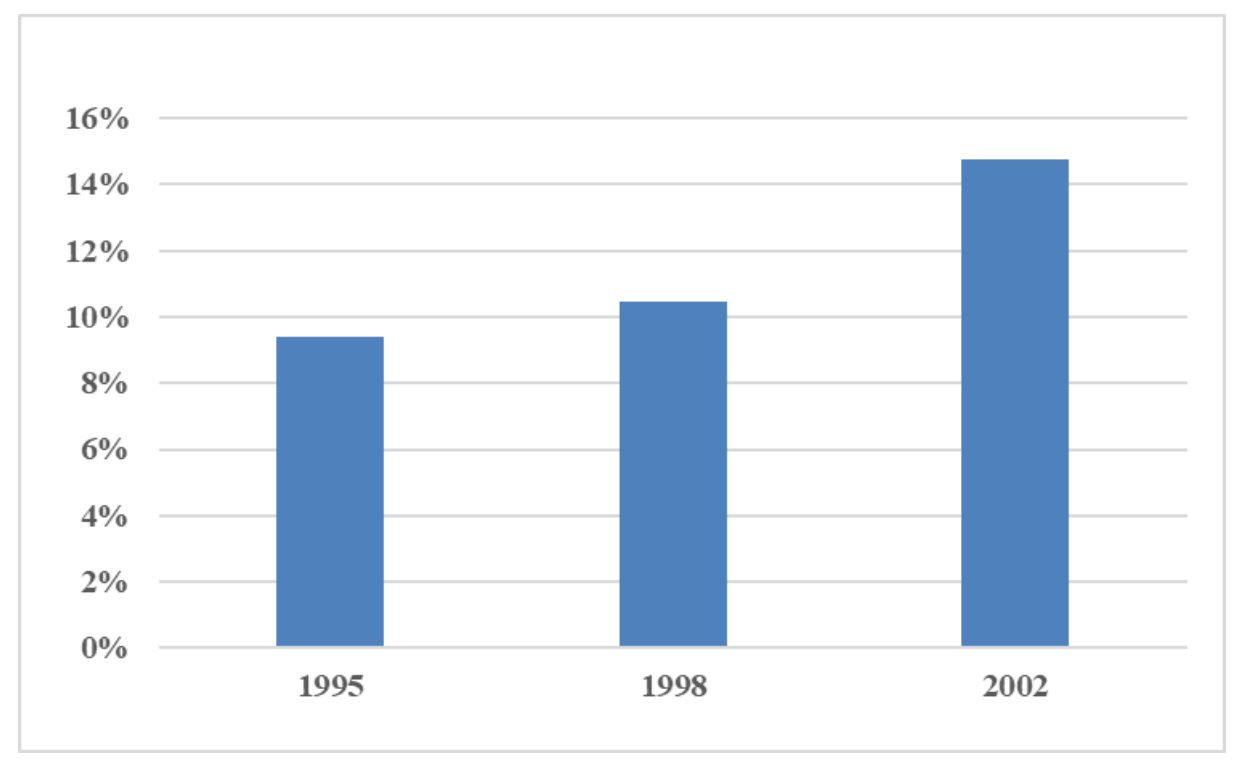

Fonte: Brasil (1995, 1998, 2002). Sinopse Estatística da Educação Superior. MEC/INEP/SEEC; IBGE - PNAD.

Além disso, os planos de governo claramente se referiram de forma negativa à rede federal de ensino superior, alegando que ela consumia excessivamente os recursos do Ministério da Educação (MEC). Por isso, a política para o ensino superior deveria realizar uma 
"reforma administrativa", ou seja, uma racionalização dos gastos a fim de tornar a administração pública mais eficiente. Em análise sobre a educação superior durante o octênio FHC, Cunha (2003) afirma que ao longo do período as diretrizes para essa etapa do ensino foram elaboradas gradualmente e tinham como objetivo claro conferir ordem ao setor privado. O Gráfico 1 retrata a divisão de IES em públicas e privadas.

É notória a expansão do setor privado ao longo dos oito anos, com um salto ocorrido a partir de 1998, o que pode ser resultado das diretrizes do PNE, encaminhado ao congresso nacional em dezembro de 1997. Ao término do Governo FHC, as IES privadas somavam 1.451, o que representou um crescimento de $112 \%$ em relação a 1995. Por outro lado, as instituições públicas - sobretudo universidades - decresceram e somavam apenas 186 estabelecimentos em 2002.

Em consonância com o aumento de instituições, as matrículas na rede privada, conforme dados do INEP, tiveram um crescimento de $129 \%$, contra $50 \%$ do setor público. Na visão de Corbucci (2002), essa discrepância é resultado do compromisso assumido pelo Governo Federal de ampliar a oferta de vagas e reconhecer novos cursos de ensino superior de forma apressada.

Gráfico 1 - Total de IES (mil) por status jurídico - 1995, 1998 e 2002

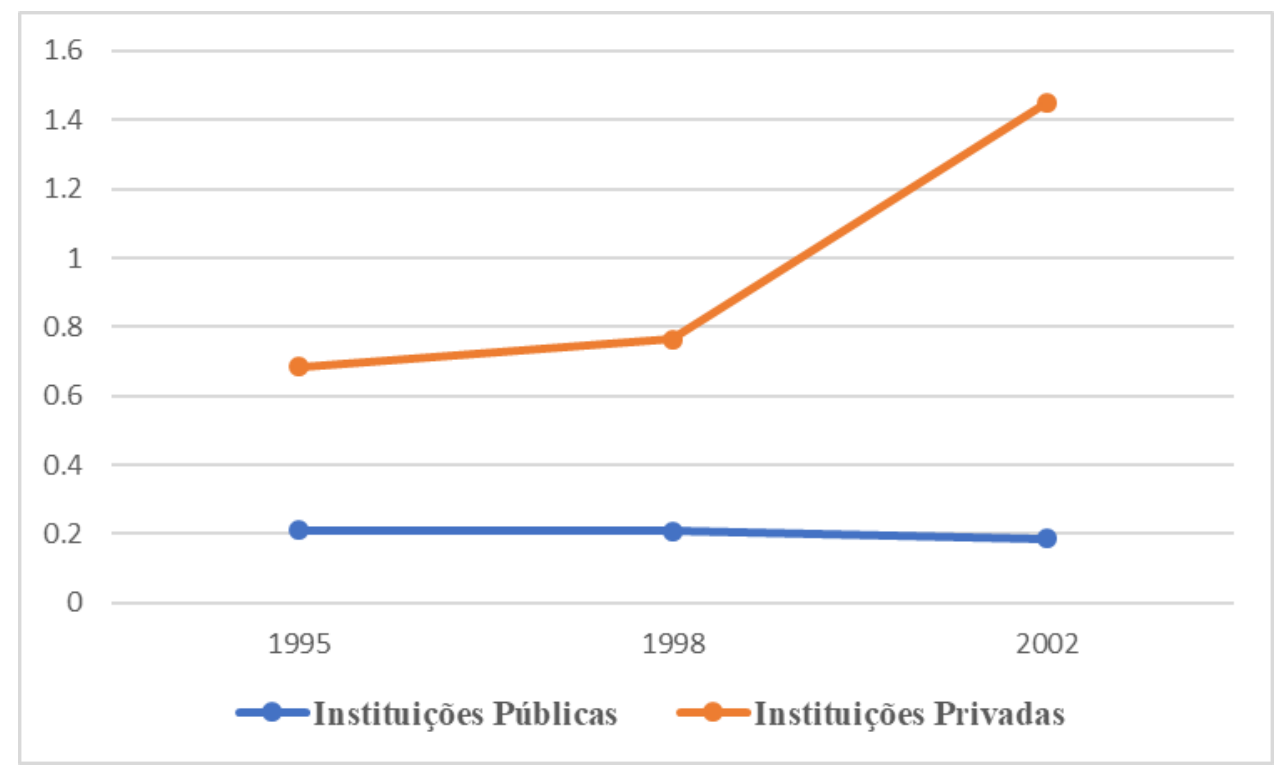

Fonte: Brasil (1995,1998,2002). Sinopse Estatística da Educação Superior. MEC/INEP/SEEC. 
Outro aspecto enfatizado pelos planos de governo - especialmente pelo segundo - diz respeito à tipologia das instituições. ${ }^{4}$ A rede física de ensino superior era por demais rígida, pois havia uma predominância de instituições baseadas em modelos e cursos tradicionais, como, por exemplo, as universidades. Esse era um fator que limitava a expansão do sistema, problema cuja solução residia na ampliação de estabelecimentos diferenciados (ou não universitários), comprometidos essencialmente com a qualidade do ensino e com a formação de recursos humanos necessários para o desenvolvimento econômico do país. No Gráfico 2 é ilustrado o comportamento da rede física durante o Governo FHC.

O Gráfico 2 mostra que, durante o Governo FHC, as faculdades isoladas apresentaram uma expansão significativa, a saber, de $71 \%$. As universidades, por outro lado, tiveram um crescimento tímido. Já os centros de educação tecnológica (CET) representavam, à época, uma pequena parcela das instituições.

Gráfico 2 - Total de IES (mil) por organização acadêmica - 1995, 1998 e 2002

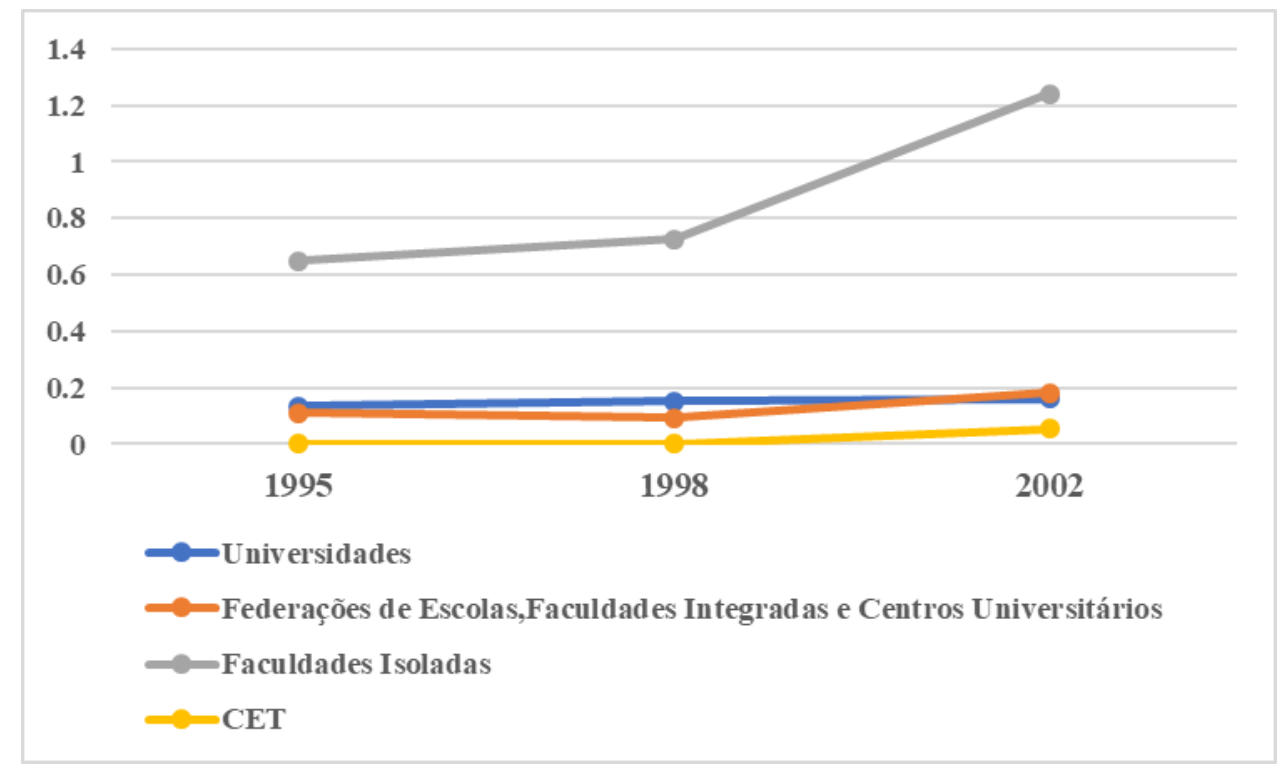

Fonte: Brasil (1995,1998,2002). Sinopse Estatística da Educação Superior. MEC/INEP/SEEC.

Embora as faculdades isoladas fossem mais numerosas, as universidades detinham o maior número de alunos matriculados. Segundo dados do INEP, as matrículas em universidades

\footnotetext{
${ }^{4}$ Segundo Soares (2002), as IES se dividiam, à época, em universidades, centros universitários, faculdades integradas, faculdades isoladas, institutos ou escolas superiores e centros de educação tecnológica, esse último em parte de caráter federal. Essa composição foi redefinida pela Lei de Diretrizes e Bases da Educação Nacional (LDB), lançada em 1996. As instituiç̃̃es universitárias tinham como prerrogativa a união do ensino com as atividades de pesquisa. Os centros universitários, novidade introduzida pela LDB, era uma modalidade que não incluía a pesquisa acadêmica, e os demais formatos supracitados ofertavam cursos em áreas específicas do conhecimento.
} 
- públicas e privadas - representavam, em 1995, aproximadamente 64\% do total de matrículas na educação superior. Em 2002, esse número caiu em dois pontos percentuais. As federações de escolas e centros universitários, porém, aumentaram sua participação em 7 pontos percentuais, passando a representar $18 \%$ do alunado em 2002.

Até agora, verificou-se que a expansão da educação superior no Governo FHC ocorreu predominantemente em instituições não universitárias e da esfera privada. Conforme apontam Chiarini e Vieira (2012), para se relacionar as matrículas ao desenvolvimento econômico do país é preciso uma análise por área de conhecimento, uma vez que a área da Engenharia é tida como estratégica para o desenvolvimento de novas tecnologias produtivas. Tal relação é apresentada na Figura 2, conforme classificação da Coordenação de Aperfeiçoamento de Pessoal de Nível Superior (CAPES).

$\mathrm{Na}$ maioria dos campos do conhecimento houve crescimento ao longo dos oito anos. Porém, não há alteração na participação relativa de cada área. A área de Engenharia/Tecnologia correspondeu, à época, a aproximadamente 7\% das matrículas nas IES nacionais.

Figura 2 - Matrículas (mil) por área do conhecimento nas IES - 1995, 1998 e 2002

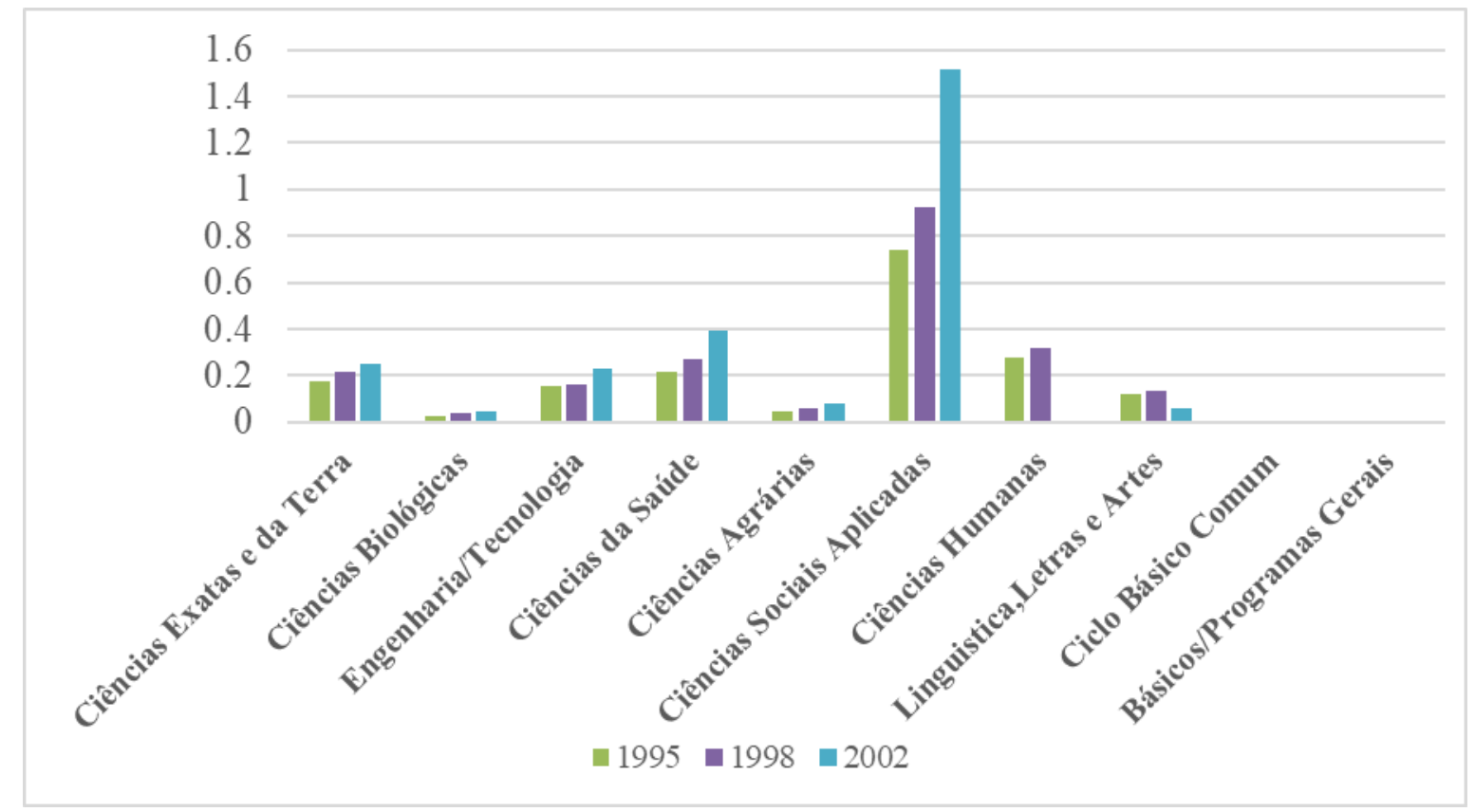

Fonte: Brasil (1995, 1998, 2002). Sinopse Estatística da Educação Superior. MEC/INEP/SEEC. Nota: Exclusive matrículas em cursos de graduação não presenciais.

Outros resultados consolidados do ensino superior dizem respeito às políticas educacionais vigentes durante o período. O Governo Federal operou uma importante reformulação na política de crédito educativo. Em 1999, ele criou o FIES, um programa que 
concedia financiamento a estudantes regularmente matriculados em cursos superiores não gratuitos e bem avaliados pelo MEC. Tal programa tinha como inspiração o Programa Crédito Educativo (CREDUC), mas esse se encontrava em péssima situação financeira devido à inadimplência dos beneficiários. Em junho de 1999, o índice de inadimplência do CREDUC atingiu 66\% do valor total financiado (CORBUCCI, 2002). Para garantir a contínua concessão de novos créditos, adotaram-se as salvaguardas (fiador e renda mínima), assim como o compartilhamento do risco futuro inerente ao crédito entre a União, as IES e o agente financeiro. $\mathrm{O}$ valor total para pagamento do FIES repassado às Mantenedoras está na Tabela 1.

Tabela 1 - Repasse do FIES às Mantenedoras, em reais (preços de2002), 1999/2002

\begin{tabular}{c|c}
\hline Ano & Valores \\
\hline 1999 & - \\
2000 & 502.864 .133 \\
2001 & 526.230 .481 \\
2002 & 565.040 .963 \\
\hline Total & 1.594 .135 .577
\end{tabular}

Fonte: Brasil (2000, 2001, 2002). DIBEN; SUDEL (2000, 2001). Caixa Econômica Federal (2002). Nota: A correção dos valores foi realizada com base no IPC-A (IBGE).

Destaca-se que o FIES tinha como foco os estudantes de baixa renda: segundo Corbucci (2002), 81,4\% dos contemplados no processo seletivo do primeiro semestre de 1999 provinham de famílias com renda de um a cinco salários mínimos. Em valores reais, houve crescimento contínuo ao longo dos anos. De 2000 a 2002, os repasses cresceram aproximadamente 12\%, totalizando um valor próximo de 1,5 bilhões de reais.

Entretanto, como ressalta Corbucci (2002), o FIES tinha uma abrangência limitada, cobrindo menos de $10 \%$ das matrículas nas IES privadas. Por isso, até 2002, não foi um mecanismo suficiente para melhorar a TBP nacional. Além disso, os recursos do programa foram distribuídos de forma inversamente proporcional ao valor da semestralidade e diretamente proporcional à demanda dos estudantes. Consequentemente, os recursos foram canalizados para os cursos mais baratos, como as licenciaturas. Cursos tradicionais como Direito e Administração são outros exemplos de cursos que receberam boa parte do contingente de beneficiários (SOARES, 2002). 


\section{O ENSINO SUPERIOR NO GOVERNO LULA (2003-2010)}

Em 2002, Luiz Inácio Lula da Silva, o Lula, foi eleito presidente do país ao derrotar o candidato José Serra do PSDB. Foi a primeira vez que o Partido dos Trabalhadores (PT) assumiu a Presidência da República. Assim como seu antecessor no cargo, Lula foi bemsucedido em sua tentativa de reeleição, estendendo o governo até 2010. Os planos de governo foram críticos ao que se observara no Governo FHC no âmbito do ensino superior, rejeitando o processo de privatização e de diversificação das instituições por sua incapacidade de propiciar a democratização do acesso ao ensino.

No entanto, conforme esses planos, o Governo Lula pretendia continuar com a política de expansão do sistema nos anos seguintes, mediante manutenção e ampliação da política de assistência aos estudantes, criação de novas universidades federais e, por fim, a ampliação de vagas nas IES públicas. Observando-se o número total de alunos matriculados em cursos de nível superior, bem como da população jovem em idade escolar, estima-se a TBP nacional, a qual se encontra na Figura 3 a seguir.

Figura 3 - TBP do Ensino Superior - 2003, 2006 e 2010

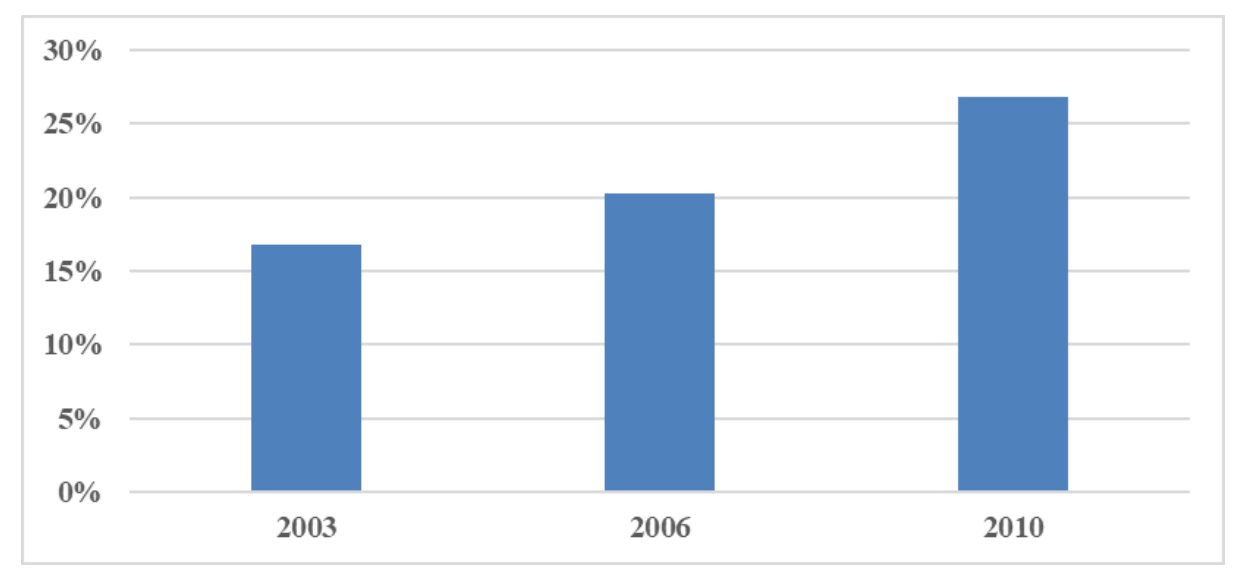

Fonte: Brasil (2003-2006-2010). Sinopse Estatística da Educação Superior. MEC/INEP/DEAES; IBGE - PNAD

De 2003 a 2010, a tipologia das instituições foi sendo constantemente modificada. Por isso, para esse período, agrupamos o total de IES em universidades, centros universitários e faculdades/centros de educação tecnológica. Assim como a TBP, o número de IES cresceu como um todo ao longo do Governo Lula. As universidades brasileiras, em particular, cresceram em ritmo inferior ao da totalidade de IES: as públicas cresceram aproximadamente $30 \%$, enquanto as privadas tiveram uma tímida expansão de aproximadamente $5 \%$. 
Em 2003, a TBP foi de aproximadamente 17\%, aumentou para 20\% em 2006 e atingiu 27\% em 2010. Como apontam os dados da PNAD/IBGE, a população brasileira em idade escolar praticamente manteve-se em 24 milhões de 2003 a 2010. Ao mesmo tempo, o crescimento das matrículas em cursos de graduação nas IES foi de aproximadamente $82 \%$. Como aponta Carvalho (2015), o Governo Lula se propôs a atuar segundo um propósito duplo: recuperar as universidades públicas - preteridas pelo governo anterior - e fixar critérios mais rigorosos para a definição de instituições universitárias. A Figura 4 reúne as informações no âmbito da organização acadêmica para o período em análise.

Figura 4 - Total de IES (mil) por organização acadêmica, 2003, 2006 e 2010

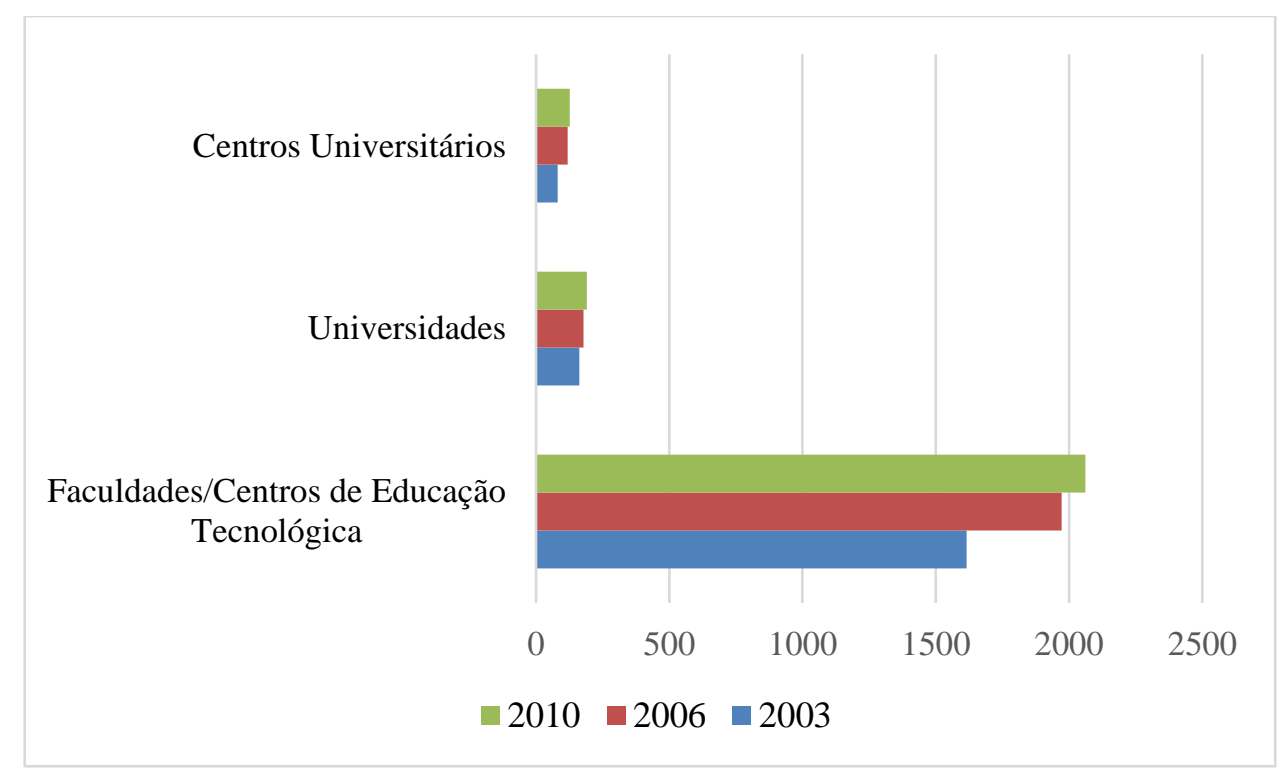

Fonte: Brasil $(2003,2006,2010)$. Sinopse Estatística da Educação Superior. MEC/INEP/SEEC.

Conforme dito anteriormente, os planos de governo se referiram negativamente ao avanço da rede privada em detrimento da rede pública durante o Governo FHC. Além disso, criticaram o controle centralizado do sistema, materializado pelo Exame Nacional de Cursos (ENC), sem uma contrapartida de melhora para o ensino das instituições. A democratização do acesso, portanto, dependia da recuperação das IES públicas. As informações relativas ao total de estabelecimentos públicos e privados são ilustradas pelo Gráfico 3.

O número de instituições públicas e privadas cresceu nesse período. Não há mudança na proporção por status jurídico, ou seja, a trajetória herdada de predomínio da esfera privada foi mantida. Nesse sentido, Carvalho (2015) afirma que a intenção dos planos de governo de incrementar a rede pública de ensino de tal modo a realçar a ação estatal não se concretizou. 
Gráfico 3 - Total de IES (mil) por status jurídico - 2003, 2006 e 2010

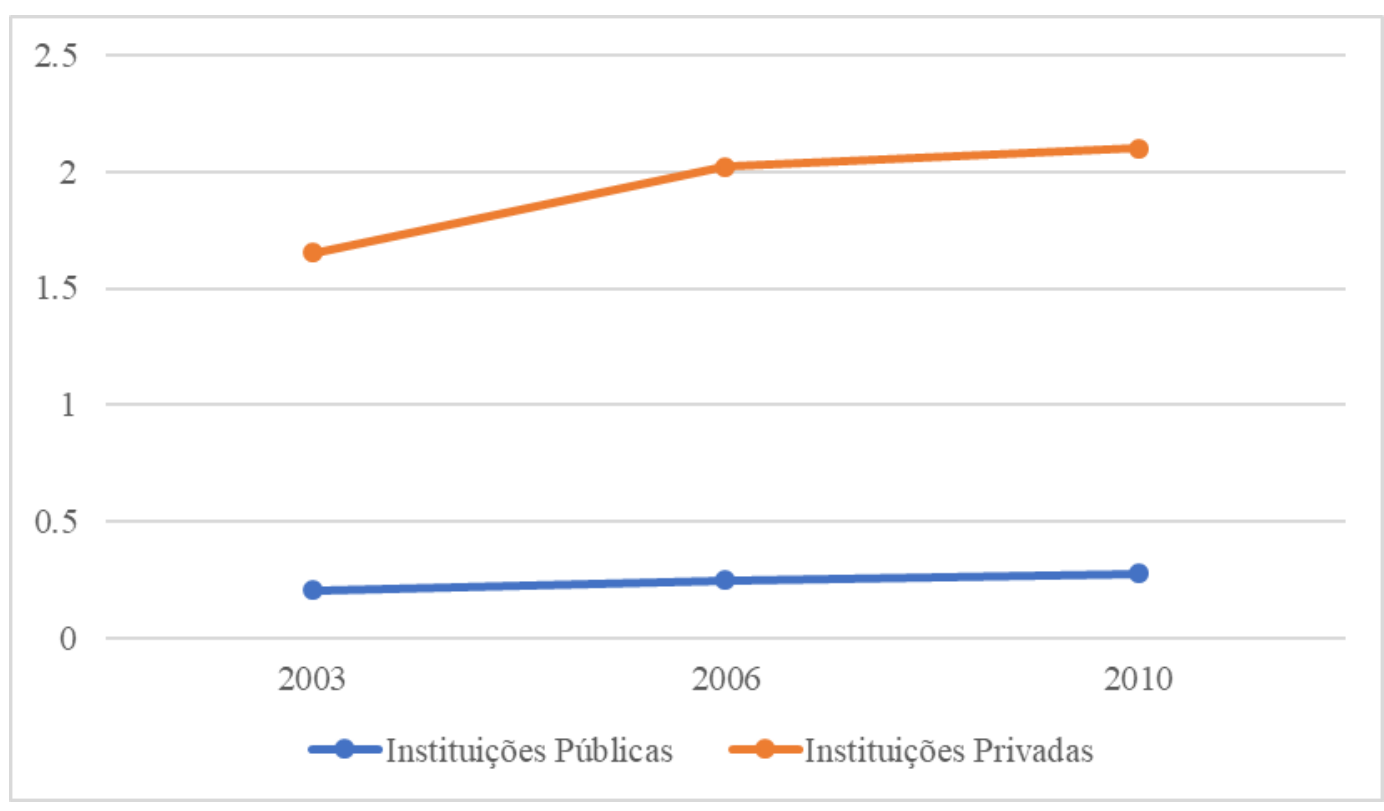

Fonte: Brasil (2003, 2006, 2010). Sinopse Estatística da Educação Superior. MEC/INEP/SEEC.

Ainda, a divisão de discentes matriculados em instituições privadas e públicas também foi mantida: segundo dados do INEP para os anos de 2003 e 2010, tal contingente se dividia a razão $74 \%$ e $26 \%$, respectivamente. Cabe ressaltar o crescimento das matrículas ligadas à rede pública de educação tecnológica, sobretudo federal, um resultado do novo rumo dado à educação tecnológica. A distribuição por área de conhecimento é ilustrada na Figura 5.

Figura 5 - Matrículas em graduação presencial por área de conhecimento

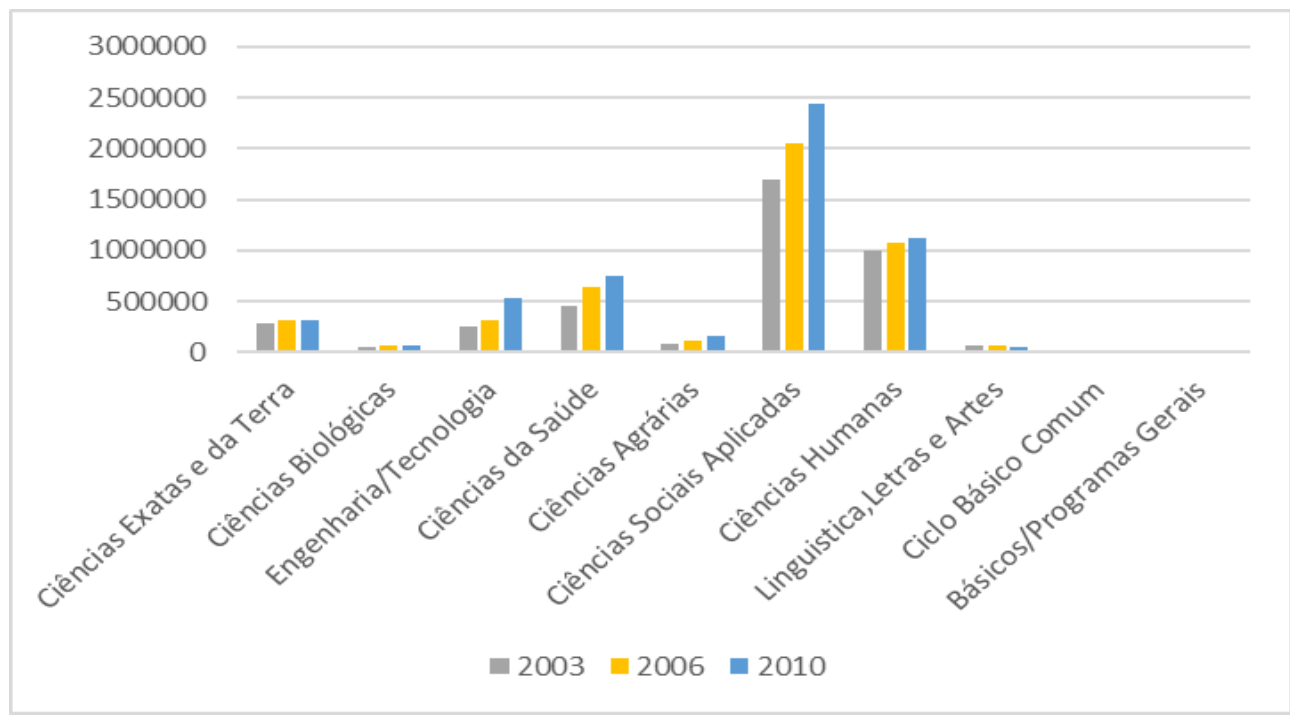

Fonte: Brasil (1995, 1998, 2002). Sinopse Estatística da Educação Superior. MEC/INEP/SEEC. Nota: Exclusive matrículas em cursos de graduação não presenciais. 
A maioria das áreas cresceu em número de matrículas. A segunda área de maior expansão foi a Engenharia/Tecnologia, sobretudo de 2006 a 2010. Ainda, essa área elevou a sua participação relativa de $7 \%$ para $10 \%$ do total do alunado matriculado no sistema de ensino superior brasileiro. Nas Ciências Agrárias o crescimento também foi notório ao longo dos anos.

A perspectiva do presente trabalho também incorpora as políticas de fomento à educação superior do país. Durante o Governo Lula, houve três grandes programas: o Programa de Apoio a Planos de Reestruturação e Expansão das Universidades Federais (REUNI), de 2007; o FIES, uma herança do governo anterior; e o Programa Universidade Para Todos (PROUNI), instituído em 2005. Esse último foi - e ainda é - um programa de concessão de bolsas integrais e parciais em cursos de graduação e sequenciais de formação específica em IES privadas. Apenas candidatos cuja renda familiar fosse de até 1 (um) salário mínimo concorreriam por bolsas integrais. Já as bolsas parciais tinham como beneficiários jovens cuja renda familiar fosse de até 3 (três) salários mínimos. Segundo Aguiar (2016), o programa foi criado a fim de corrigir dois problemas estruturais: a exclusão das camadas mais desfavorecidas e a (falta de) fiscalização da IES filantrópicas e sem fins lucrativos. A Figura 6 mostra o número de bolsas ocupadas desde a criação do programa até o término do Governo Lula.

Figura 6 - Número de bolsas ocupadas pelo Prouni (mil) nas IES privadas do Brasil

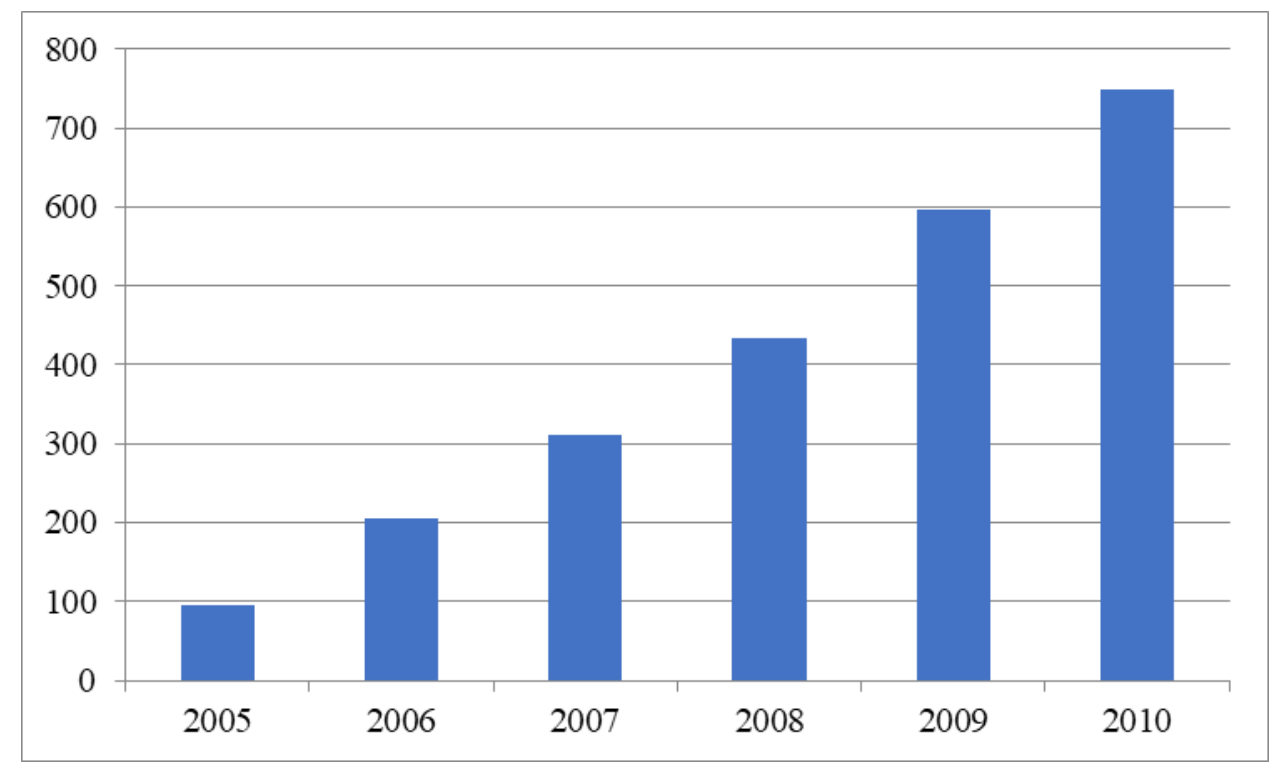

Fonte: Brasil (2010). Balanço de governo 2003-2010.

Nota: Trata-se da quantidade acumulada.

Houve um crescimento contínuo de bolsas ocupadas pelos estudantes. Após seis anos de vigência, o programa beneficiou um total de 748 mil jovens. Destaca-se que $48 \%$ dos 
beneficiados foram jovens afrodescendentes. No entanto, como afirma Aguiar (2016), foram várias as críticas ao programa. As mais triviais afirmaram que o programa apoiou o processo de privatização da educação superior, visto que se transferiram recursos dos cofres públicos para o setor privado. Além disso, criticou-se o programa em razão da falta de controle público sobre a qualidade das instituições participantes, o que redundou para os beneficiários do programa - uma fração da população jovem carente - no oferecimento de cursos de baixa qualidade.

Também houve a reformulação do FIES, criado em 1999. Segundo Aguiar (2016), algumas mudanças introduzidas foram: a disponibilização do fluxo contínuo do programa, o que abriu a possibilidade de concessão do financiamento do curso a qualquer tempo; a ampliação da carência para 18 meses; extensão do prazo para pagamento para 3 (três) vezes em relação ao período de utilização do financiamento. A Tabela 2 mostra a evolução do repasse de recursos às mantenedoras do programa.

Tabela 2 - Repasse do FIES às Mantenedoras em reais (preços de 2010) - 2003/2010

\begin{tabular}{lc}
\hline Ano & Valores \\
\hline 2003 & $900.277 .028,22$ \\
2004 & $852.506 .853,50$ \\
2005 & $764.376 .515,62$ \\
2006 & $883.667 .754,42$ \\
2007 & $807.970 .638,57$ \\
2008 & $754.678 .722,10$ \\
2009 & $870.896 .223,91$ \\
2010 & $635.543 .140,92$ \\
\hline Total & $6.469 .916 .877,26$
\end{tabular}

Fonte: Brasil (2003, 2004, 2005, 2006, 2007, 2008, 2009 e 2010). CAIXA ECONÔMICA FEDERAL. Nota: Em 2007 e 2008, considerou-se o valor de créditos orçamentários descentralizados e liquidados ao final dos exercícios, pois não havia informações de repasse às mantenedoras.

A partir de 2007, com a criação do Plano de Desenvolvimento da Educação (PDE), o FIES foi considerado como alternativa para melhorar os índices de educação do país. Pela Tabela 2, verifica-se que tanto no primeiro quanto no segundo governo houve relativa estabilidade no valor dos recursos, exceto em 2010, quando o relatório de gestão contabilizou um decréscimo nos valores.

Em 2007, foi lançado o REUNI. Segundo Carvalho (2015), as principais metas do programa foram a evolução paulatina da taxa de conclusão dos alunos de graduação presencial 
para 90\%, a elevação da proporção de alunos de graduação por professor para 18 (dezoito), a diversificação dos cursos de graduação e a propagação do ensino a distância. A Figura 7 retrata as despesas empenhadas com o REUNI em específico.

O programa foi a materialização da política de expansão do segmento federal, cuja finalidade era reduzir as disparidades regionais do país (CARVALHO, 2015). Em valores reais, nota-se que até 2010 o volume de recursos destinado ao programa foi praticamente quadruplicado. No total, gastou-se cerca de 1,4 bilhões de reais. O REUNI mais do que dobrou o número de vagas nas universidades federais e criou 14 novas, além de muitos campi no interior (BRASIL, 2010).

Figura 7 - Despesas empenhadas no REUNI, em milhões de reais (2010), 2008-2010

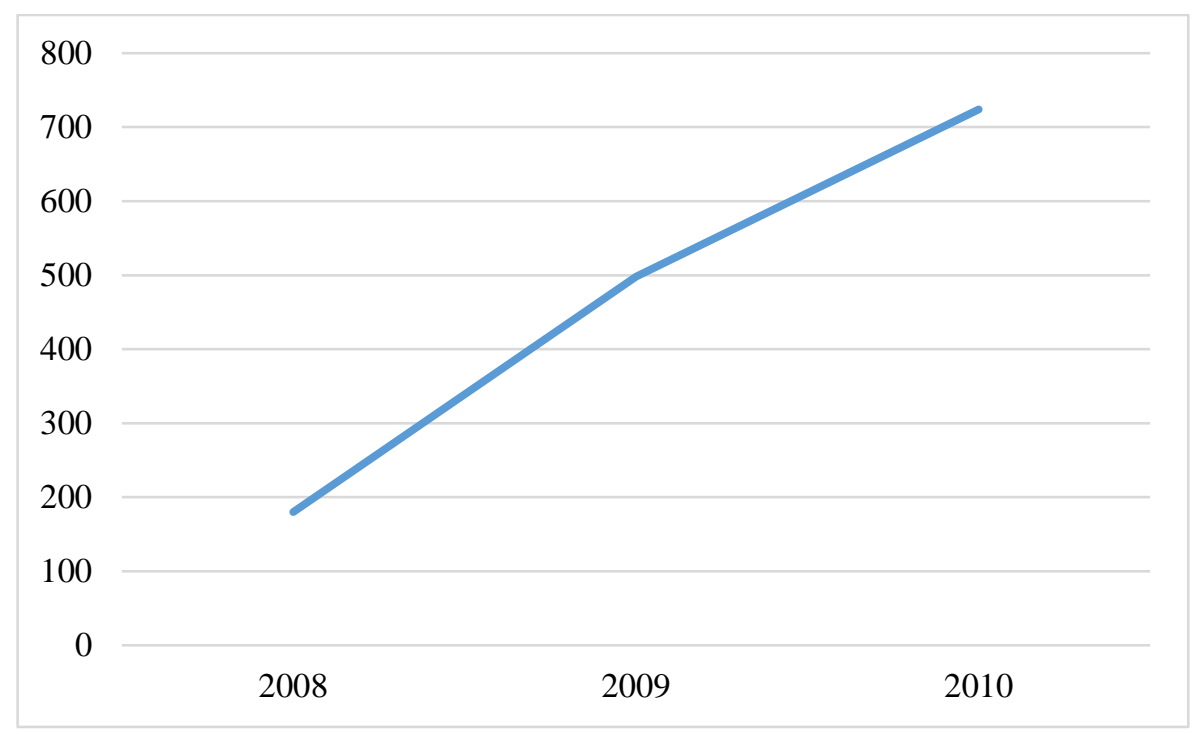

Fonte: SIGA Brasil, Senado Federal.

Nota: A correção dos valores foi realizada com base no IPC-A (IBGE). O instrumento utilizado foi a Calculadora do Cidadão, do Banco Central do Brasil.

\section{CONSIDERAÇÕES FINAIS}

O tema do desenvolvimento econômico dispõe de vasto patrimônio teórico. O presente artigo, longe de explorá-lo de forma integral, delimitou um sentido estrito para o conceito e procurou associá-lo aos resultados consolidados da educação superior do país durante dois governos da recente história brasileira.

Como é sabido, as universidades, os centros universitários e demais instituições, são responsáveis pela formação de quadros profissionais em nível superior. Essa função é de suma importância para o desenvolvimento tecnológico e econômico de economias em atraso. Como 
ressalta Lall (2003), um dos papéis das IES é desenvolver e aprimorar as capacidades locais de aprendizado de indivíduos e firmas, e, nesse sentido, os cursos de Engenharia, em razão de sua dimensão tecnológica, merecem uma atenção especial.

Cabe ao Governo Federal articular o funcionamento das IES. O presente trabalho identificou que os planos de governo dos presidentes FHC e Lula defenderam fortemente a ampliação da educação superior no Brasil. O primeiro dos governos, pela via privada, pois adotou um enfoque crítico quanto à importância, o desempenho e os custos das IES públicas. Já o Governo Lula teve uma intenção diferente, a saber, de restaurar as IES públicas e propiciar uma democratização do acesso, algo ausente no mandato presidencial anterior, segundo os programas de governo.

No que se refere aos resultados consolidados, o presente trabalho mostrou que a rede física cresceu e se diversificou durante os dezesseis anos. O setor privado foi muito incrementado de 1995 a 2002, enquanto as universidades públicas permaneceram estagnadas. Embora no Governo Lula a distribuição por status jurídico tenha se mantido, houve um crescimento das universidades públicas, em especial no segundo mandato. Esse crescimento foi objetivo do programa REUNI, o qual apresentou um crescimento real de despesas empenhadas, e que levou à criação e ampliação da esfera pública e federal de ensino superior.

$\mathrm{Na}$ análise do alunado, notou-se uma diferença entre os governos no que diz respeito à classificação e distribuição segundo a área de conhecimento. Se no Governo FHC não houve alteração no padrão de distribuição, no Governo Lula a área de Engenharia/Tecnologia passou a representar $10 \%$ do total dos discentes matriculados em cursos de graduação, contra $7 \%$ do início do primeiro governo. Foi a segunda área a apresentar a maior taxa de crescimento em termos absolutos.

Ambos os governos foram relativamente exitosos com suas políticas públicas. O FIES mostrou-se estável financeiramente desde a sua criação. Segundo dados dos relatórios de gestão disponibilizados pela Caixa Econômica Federal, o número de financiamentos durante o Governo FHC foi, em média, de 54 mil por ano. No Governo Lula, caiu para 51 mil, porém somando à média anual de bolsas ocupadas do PROUNI, foi de aproximadamente 176 mil. Esse número é mais do que o triplo do governo anterior. Entretanto, nenhum dos programas analisados propôs uma expansão de matrículas ancorada na área da Engenharia. Depreende-se que os esforços foram válidos para a ampliação de profissionais qualificados, mas não contribuíram para potencializar as capacidades locais de aprendizado. 
Por fim, cabe ressaltar duas dentre as diversas limitações deste trabalho. O processo de desenvolvimento econômico não se restringe a uma dimensão tecnológica, embora ela seja imprescindível ao conceito. Ademais, um aprofundamento das relações entre o processo formativo superior e o desenvolvimento econômico exigiria a análise de outros indicadores, de uma região em específico, ou, ainda, de uma análise comparativa com economias em nível similar de desenvolvimento.

\section{REFERÊNCIAS}

AGUIAR, V. Um balanço das políticas do governo Lula para a educação superior: continuidade e ruptura. Revista de Sociologia e Política, Curitiba, v. 24, n. 57, p. 113-126, 2016. Disponível em: <http://bit.ly/2nrhkmo>. Acesso em 28 nov. 2017

AMSDEN, A.H. A ascensão do "resto". São Paulo: Editora da Unesp, 2004.

AROCENA, R.; SUTZ, J. Conhecimento, inovação e aprendizado: sistemas e políticas no Norte e no sul. In: LASTRES, H.; CASSIOLATO, J.; ARROIO, A. (Org.). Conhecimento, Sistemas de inovação e desenvolvimento. Rio de Janeiro: UFRJ, 2005. p. 17-50.

BRASIL. Governo Federal. Balanço de governo 2003-2010. 3. Educação. Brasília, DF, 2010. Disponível em <http://bit.ly/2nt3v78>. Acesso em: 28 nov. 2017.

CAIXA ECONÔMICA FEDERAL. Diretoria de Transferência de Benefícios - DIBEN. Superintendência Nacional de Distribuição de Serviços ao Cidadão - SUDEL. F I E S: financiamento estudantil. Relatório de gestão: exercício 2000, 2001 e 2002. Brasília, DF, 2003. Disponível em: < http://bit.ly/2Bevm0U>. Acesso em: 05 out. 2017.

CAIXA ECONÔMICA FEDERAL. Fundo de financiamento ao estudante do ensino superior - FIES. Relatório de gestão: exercício 2003, 2004, 2005,2006,2007,2008,2009 e 2010. Brasília, DF, 2010. Disponível em: < http://bit.ly/2Bevm0U>. Acesso em: 28 nov. 2017.

CARVALHO, C.H.A. A política pública de expansão para a educação superior entre 1995 e 2010: uma abordagem neoinstitucionalista histórica. Revista Brasileira de Educação, Rio de Janeiro, v. 20, n. 60, p. 51-76, 2015. Disponível em: < http://bit.ly/2jbvgfX >. Acesso: 28 nov. 2017

CHIARINI, T.; VIEIRA, K.P. Universidades como produtoras de conhecimento para o desenvolvimento econômico: sistema superior de ensino e as políticas de CT\&I. Revista Brasileira de Economia, Rio de Janeiro, v.66, n.1, p 117-132, jan. /mar. 2012. Disponível em: < http://bit.ly/2yCQ5qr>. Acesso: 28 nov. 2017

CORBUCCI, P.R. Avanços, limites e desafios das políticas do MEC para a educação superior na década de 1990: ensino de graduação. Brasília, DF: Ipea, 2002. (Texto para 
discussão, 869). Disponível em: <http://bit.ly/2ieM8BU>. Acesso em: 01 nov. 2017.

CUNHA, Luiz Antônio. O ensino superior no octênio FHC. Educação \& Sociedade, Campinas, SP, v.24, n. 82, p. 37-61, 2003.

FURTADO, C. Pequena introdução ao desenvolvimento: enfoque interdisciplinar. São Paulo: Companhia editora nacional, 1980.

INSTITUTO BRASILEIRO DE GEOGRAFIA E ESTATÍSTICA - IBGE. Pesquisa nacional por amostra de domicílios. Rio de Janeiro, v.17, n.1. p.1-120, 1995. Disponível em: <http://bit.ly/2jriL2L>. Acesso em: 01 nov.17

INSTITUTO BRASILEIRO DE GEOGRAFIA E ESTATÍSTICA - IBGE. Pesquisa nacional por amostra de domicílios. Rio de Janeiro, v. 20, n.1, p. 1-113, 1998. Disponível em: <http://bit.ly/2zCSaX2>. Acesso em: 01 nov.17

INSTITUTO BRASILEIRO DE GEOGRAFIA E ESTATÍSTICA - IBGE. Pesquisa nacional por amostra de domicílios. Rio de Janeiro, v.23, n.1,p.1-113, 2002. Disponível em: < http://bit.ly/2AIsvKl>. Acesso em: 01 nov.17

INSTITUTO BRASILEIRO DE GEOGRAFIA E ESTATÍSTICA - IBGE. Pesquisa nacional por amostra de domicílios. Rio de Janeiro, v.24, n.1, p.1-120,2003. Disponível em: <https://bit.ly/2DaSnjR >. Acesso em: 01 nov.17

INSTITUTO BRASILEIRO DE GEOGRAFIA E ESTATÍSTICA - IBGE. Pesquisa nacional por amostra de domicílios. Rio de Janeiro, v.27, n.1, p.1-125,2006. Disponível em: < https://bit.ly/2GaRtrG >. Acesso em: 01 nov.17

INSTITUTO BRASILEIRO DE GEOGRAFIA E ESTATÍSTICA - IBGE. Censo

Demográfico 2010. Rio de Janeiro,2011. Disponível em: < https://bit.ly/2LsDviS>. Acesso em: 01 nov. 17

INSTITUTO NACIONAL DE ESTUDOS E PESQUISAS EDUCACIONAIS ANÍSIO TEIXEIRA - INEP. Sinopse Educação Superior. Brasília, DF, 1995, 1998,2002. Disponível em: <http://bit.ly/2httV2Z> Acesso em: 05 out. 2017.

INSTITUTO NACIONAL DE ESTUDOS E PESQUISAS EDUCACIONAIS ANÍSIO TEIXEIRA - INEP. Serviço de Estatística da Educação e Cultura - SEEC. Sinopse Educação Superior. Brasília, DF, 2003,2006 e 2010. Disponível em: <http://bit.ly/2httV2Z> Acesso em: 05 out. 2017.

LALL, S. Technology and industrial development in an era of globalization. In: CHANG, H. (Org.). Rethinking development economics. Londres, Reino Unido: Anthem Press, 2003. Disponível em: < http://bit.ly/2k3Yb5d>. Acesso em: 08 nov. 2017.

PARTIDO DA SOCIAL DEMOCRACIA BRASILEIRA - PSDB. Mãos à obra, Brasil: proposta de governo. [1994]. Disponível em: < http://bit.ly/2B6X5R3> Acesso em: 05 out. 2017. 
PARTIDO DOS TRABALHADORES - PT. Programa de Governo 2002 - Coligação Lula Presidente. [S.1.], 2002. p. 1-73. Disponível em: <http://bit.ly/2ifsvcN > Acesso em: 28 nov.2017

SOARES, M. S. A. (Coord.). A Educação Superior no Brasil. Porto Alegre: IESALC Unesco nov. 2002. Disponível em: <http://bit.ly/2hytx71 > Acesso em 01 nov. 2017.

VELHO, L. Formação de mestres e doutores e sistema de inovação. Rio de Janeiro: RedeSist, 2007. (Research Paper, 05/07). Disponível em: 〈http://bit.ly/2hRMOgA>. Acesso em: 08 nov. 2017. 